\title{
From response to transformation: how countries can strengthen national pandemic preparedness and response systems
}

\author{
Victoria Haldane and colleagues delve into the characteristics of national responses to covid-19. \\ They suggest actionable steps at a national level that can guide states to achieve the independent \\ panel's recommendations for making this the last pandemic
}

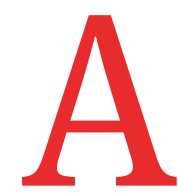

$\mathrm{s}$ the second year of the covid19 pandemic ends, we are confronted with the reality that national responses thus far have resulted in more than 259 million cases and 5.17 million deaths globally as of 23 November 2021. Thus, we reflect on the path that led us here and lessons to prevent further health, social, and economic losses related to the pandemic. ${ }^{1}$ ${ }^{2}$ Examining the quality of early efforts to

\section{REY MESSAGES}

- As we enter the third year of the covid-19 pandemic, we are at a pivotal moment to consider the characteristics of national responses, to understand our next steps and to prepare for future infectious hazards

- High performing national responses to covid-19 are characterised by coordinating, developing, and strengthening a suite of public health, health system, and socioeconomic measures to prevent or break chains of transmission in communities

- Low performing countries' national approaches were hindered by devaluing, denial, delays, and distrust. Interventions ultimately prevented co-ordinated national efforts or rendered them ineffective in breaking chains of transmission in communities

- To implement recommendations of the Independent Panel for Pandemic Preparedness and Response, we propose 15 actionable next steps for responding to emergent pandemic threats, preparing and maintaining resilient health systems for pandemic response, and transforming to build intersectional approaches centred on community trust and enabled by equitable societies mitigate the spread and impact of covid-19 can shed light on strengths and weaknesses in national pandemic responses. These responses not only shaped the course of the pandemic in 2020, but also laid a foundation for enduring impacts on health, societies, and the economy. They influenced decisions about vaccine prioritisation and delivery programmes, and gave evidence to support the view that covid-19 is an endemic disease. ${ }^{3-6}$ Thus, we are now at a pivotal moment to consider the characteristics of national responses to covid-19 and take stock of the qualities that differentiate a high performing from a low performing approach.
Based on an analysis of 28 national responses to covid-19 in the first year of the pandemic (box 1), we discuss the characteristics of high performing responses and low performing responses, and offer a way forward to sustain momentum and move towards implementing the recommendations of the Independent Panel for Pandemic Preparedness and Response. ${ }^{1}$ High performing responses are defined as those countries that had the least number of deaths directly related to covid-19 per capita in November 2020, and low performing those with the highest fatality numbers (box 1).

\section{Box 1: Methods}

We selected 28 countries on 6 November 2020, reflecting the reported death toll at the time (box 2). Countries selected include positive and negative outliers in relation to reported covid19 deaths per capita among highly populous countries, as well as countries in the middle ground from different regions and with widely varying health systems and economic statuses. Given the evolving nature of the pandemic, we acknowledge that performance measured in reported deaths per capita has since changed. Ethical approval was obtained from the National University of Singapore.

Three complementary methods were adopted and triangulated to analyse national responses to covid-19:

- Literature review-Using standardised methods, we identified peer reviewed papers and public reports that examined national and subnational policy responses and extracted data for each country on five dimensions comprising 62 items. The dimensions and items were identified through a review of 14 existing frameworks.

- Semi-structured interviews and national government submissions-A total of 43 interviews and written submissions were provided between November 2020 and April 2021. Semistructured interviews with covid-19 national experts in policy, operations, and academia were recorded and transcribed in full. Interviewees were based across Europe, North America, South America, Africa, and Asia, with representatives spanning the four sectors. All interviews were coded through an inductive approach and thematic analysis, using QSR NVivo 12 Software, drawing on techniques of the constant comparison method.

- Validation of country specific data-Semi-structured interviews, written consultations, and round table discussions were conducted with 45 country experts. When we identified conflicting information from different sources, we validated our data by contacting experts to help address and resolve inconsistencies. In March 2021, national and international experts in covid-19 policies participated in two round table discussions. Experts reflected on the findings and provided written or verbal feedback. Experts also provided short presentations of their own countries, which were then used by the research team to validate the data in the report. 


\section{Box 2: Selected countries}

- Africa-Liberia, Mozambique, Niger, Nigeria, Uganda

- Asia Pacific-China, Fiji, India, Japan, New Zealand, Pakistan, Singapore, South Korea, Sri Lanka, Thailand, Vietnam

- Europe-Germany, Russia, Spain, Sweden, UK

- Middle East-Egypt

- North America-Mexico, US

- South America-Argentina, Brazil, Peru, Uruguay

\section{High performing responses: partner, coordinate, develop, and strengthen}

High performing responses during the first year of the pandemic were characterised by approaches and actions to partner, coordinate, develop, and strengthen a suite of public health, health system, and socioeconomic measures to prevent or break chains of transmission in communities. National approaches were of course informed by broader contextual factors, such as history, geography, politics, economics, trust, recent history responding to outbreaks, and other antecedents shaping decisions, including at the highest level of government. Yet, when high performing country responses during 2020 are drawn together, these four common themes persist.

High performing countries' responses were informed by partnership on multiple levels, through a whole-of-government approach, engaging with communities, and participating in purchasing partnerships to secure resources (table $1)$. High performing countries also showed coordination at all levels of the response. Uruguay is a case in point. Covid-19 coordination bodies were established at the national and subnational levels, with the president providing overall leadership. ${ }^{7}$ The Ministry of Public Health led the national response, with reports of strong coordination between the national ministries and departmental health directorates, which efficiently implemented protocols and contingency plans. ${ }^{8}$ High performing countries also coordinated to ensure adequate translation of evidence into policy and practice. In Mozambique, for example, the Technical-Scientific Commission was convened to include those with expertise in public health, media, social science, and other sectors to inform the national response. ${ }^{9}$

High performing countries focused on development, including increasing health system capacity. Singapore activated its private primary care clinics under the
Public Health Preparedness Clinics scheme to provide triage support and government subsidised treatment (based on haze events and H1N1), and the National Centre for Infectious Diseases, a 330 bed facility, provided specialised infectious disease services (based on experience with severe acute respiratory syndrome). ${ }^{10-12}$ The Singapore government further prioritised domestic research and development, coupled with production, to ensure resource availability. South Korea strengthened relationships with private sector partners and biotechnology companies in the years between the outbreak of Middle East respiratory syndrome and covid19 , resulting in timely public-private partnerships that delivered early diagnostic reagents for covid-19. In communities, high performing countries developed people centred communication strategies. ${ }^{13}$ Liberia even trained its community leaders on the epidemiology of the disease to support containment efforts, and the Thai government deployed its extensive network of one million village health workers to disseminate and amplify messages in the community. ${ }^{14}$ New Zealand is another example of robust and people centred communication by design, with intention to reach all communities. ${ }^{1516}$ Indeed, the government's emergency plan explicitly considered Indigenous groups and their access to healthcare and welfare services, although some inequalities persist. ${ }^{17}$

\section{Low performing responses: devalue, denial, delay, and distrust}

Many low performing responses appeared to have comprehensive approaches on paper. However, caveats and gaps exist, which, when taken together, failed to protect communities from covid-19. Overall, these national approaches were hindered in various ways and to varying degrees by devaluing, denial, delays, and distrust that ultimately either prevented coordinated national efforts, or rendered them ineffective in breaking chains of transmission.

While low performing countries had pandemic preparedness plans, these were devalued and rendered ineffective by a lack of adequate infrastructure to rapidly mobilise and sustain outbreak response measures (table 2). This was exacerbated by most low performing countries denying the threat of covid-19 either through word or action. ${ }^{18}$ In countries where heads of state openly denied the risk and severity of covid19 (eg, Brazil, Mexico, UK, US), pandemic response plans were simultaneously devalued at the highest end of politics, hindering governments, government institutions, and the bureaucratic apparatus from enacting or developing plans. ${ }^{19}$ The denial of scientific evidence was compounded by a failure of leadership to take responsibility or make cohesive strategies towards breaking chains of transmission in communities. ${ }^{2021}$ Similarly, these countries often had historically underfunded public health systems, rendering the supporting infrastructure unable to quickly identify outbreaks and take rapid and comprehensive action to break chains of transmission. ${ }^{22}$ Denial of social and economic supports in low performing countries largely affected those working in the informal labour market, particularly in countries with lengthy lockdown measures. ${ }^{2324}$

Delays featured in all low performing responses to varying degrees. Many countries took a "wait-and-see" approach and delayed launching response mechanisms, making decisions, and changing course based on evolving scientific evidence. The British government has oscillated between holding off public health measures to spare the economy and strict lockdowns when the public health system was already stretched to its limits with covid-19 patients. ${ }^{2526}$ However, these delays in changing approaches, especially in the beginning, have had detrimental effects on rates of covid-19 infection and deaths as hospitals and the health workforce were already at capacity limits. Crucially, the government created blanket regulations without further consideration of how lockdowns affect specific populations. ${ }^{27}$

Distrust was a powerful undercurrent throughout low performing national responses. Concerningly, in many low performing countries, leadership was sceptical or dismissive of emerging scientific evidence, which contributed to undermining public trust in the response. This was exacerbated in many low performing countries by political leadership politicising the pandemic. In the lead up to Uganda's presidential election in January 2021, the UN High Commissioner for Human Rights accused authorities of enforcing covid-19 restrictions "more strictly to curtail opposition electoral campaign activities in a discriminatory fashion." 28

\section{The middle ground: an ongoing and inequitable global pandemic}

These broad characterisations, while useful to conceptualise the relative strengths 


\begin{tabular}{|c|c|c|c|c|}
\hline & Partner & Coordinate & Develop & Strengthen \\
\hline $\begin{array}{l}\text { Prior experiences and } \\
\text { preparedness }\end{array}$ & $\begin{array}{l}\text { Previous partnerships with } \\
\text { communities leveraged for } \\
\text { outbreak response and risk } \\
\text { communications }\end{array}$ & $\begin{array}{l}\text { Experience coordinating across } \\
\text { sectors to mobilise a response }\end{array}$ & $\begin{array}{l}\text { Previous investment in public } \\
\text { health and outbreak response } \\
\text { infrastructure }\end{array}$ & $\begin{array}{l}\text { Ongoing strengthening of } \\
\text { outbreak surveillance networks }\end{array}$ \\
\hline Scientific advice & $\begin{array}{l}\text { Worked with experts to form } \\
\text { multidisciplinary committees } \\
\text { to advise leadership on the } \\
\text { response }\end{array}$ & $\begin{array}{l}\text { Efforts to translate evidence into } \\
\text { action by working across sectors } \\
\text { and with communities }\end{array}$ & $\begin{array}{l}\text { Efforts to create new } \\
\text { technologies (eg, test kits) } \\
\text { and contribute to covid-19 } \\
\text { knowledge generation }\end{array}$ & Trust in scientific advice \\
\hline Governance and leadership & $\begin{array}{l}\text { Whole-of-government } \\
\text { approaches across sectors. } \\
\text { Public-private approaches that } \\
\text { are cost effective, accountable, } \\
\text { and transparent }\end{array}$ & $\begin{array}{l}\text { Multi-ministry task forces or } \\
\text { committees }\end{array}$ & $\begin{array}{l}\text { Financing mechanisms to } \\
\text { provide relief for businesses, } \\
\text { individuals, and families }\end{array}$ & $\begin{array}{l}\text { Policies to reduce financial } \\
\text { barriers to covid-19 testing and } \\
\text { treatment }\end{array}$ \\
\hline Health systems and services & $\begin{array}{l}\text { Engage the community in the } \\
\text { planning of services }\end{array}$ & $\begin{array}{l}\text { Triage and referral processes } \\
\text { with primary and community } \\
\text { care }\end{array}$ & $\begin{array}{l}\text { Capacity in medical facilities } \\
\text { through temporary facilities and } \\
\text { postponing elective procedures. } \\
\text { Networks of laboratories }\end{array}$ & $\begin{array}{l}\text { Primary and community care. } \\
\text { Access to and use of digital } \\
\text { technologies }\end{array}$ \\
\hline Public health & $\begin{array}{l}\text { Community health workers or } \\
\text { other community leaders in high } \\
\text { risk areas or settings }\end{array}$ & $\begin{array}{l}\text { Proactive testing and contact } \\
\text { tracing strategies }\end{array}$ & $\begin{array}{l}\text { Quarantine and isolation } \\
\text { facilities }\end{array}$ & Active surveillance mechanisms \\
\hline Social and economic supports & $\begin{array}{l}\text { Multisectoral action to ensure } \\
\text { protection against food, housing, } \\
\text { and income insecurity }\end{array}$ & $\begin{array}{l}\text { Involve community groups and } \\
\text { local organisations to deliver } \\
\text { social supports }\end{array}$ & $\begin{array}{l}\text { Financial mechanisms to ensure } \\
\text { free covid-19 testing and } \\
\text { treatment }\end{array}$ & $\begin{array}{l}\text { Social and financial protections } \\
\text { for communities and small } \\
\text { businesses }\end{array}$ \\
\hline
\end{tabular}

and weaknesses of national pandemic responses, are by no means mutually exclusive. Examples of devaluing, denial, delays, and distrust are seen in aspects of high performing responses, just as low performing countries made attempts on varying scales and to varying degrees to partner, coordinate, develop, and strengthen their responses. Indeed, pandemic responses are complex systems, comprised of feedback loops and characterised by path dependencies and non-linear interactions that challenge evaluative efforts.

As a result, many countries' responses to covid-19 fell in the middle ground during 2020, exhibiting both high and low performing characteristics. While some countries took aggressive action to strengthen their response after an initial surge, others were more conservative. Their strategies aimed for containment to the greatest extent possible, but were often inconsistent over time. The need to maintain public support, and changes in public health policies, allowed cases to surge in waves. These policies were backed by social and economic supports that were temporary or did not reach the whole population. Some countries only took robust efforts to protect their most vulnerable after significant outbreaks in crowded settings or in specific populations, such as migrant workers. The whole of a national response to covid-19 is more than the sum of its parts. If what countries did was often similar, how and when they implemented measures, and when they took action differed.
This middle ground approach, and the absence of meaningful global collaboration, has failed to lead us to a better and fairer "post-covid world." Instead, we see a doubling down of the status quo, where those most marginalised are disproportionately affected by an ongoing pandemic. Since its emergence in late 2019, covid-19 has led to a dramatic loss of human life, left health systems and health workers in shock and stress, and triggered economic and social disruption on a global scale, with the most devastating effects on already vulnerable populations.

After two years of pandemic response, countries continue to oscillate between learning to partner, coordinate, develop, and strengthen, and continuing to devalue, deny, delay, and distrust. Against

\begin{tabular}{|c|c|c|c|c|}
\hline & Devalue & Denial & Delays & Distrust \\
\hline $\begin{array}{l}\text { Prior experiences and } \\
\text { preparedness }\end{array}$ & $\begin{array}{l}\text { Pandemic preparedness } \\
\text { plans did not have adequate } \\
\text { infrastructure to rapidly mobilise }\end{array}$ & $\begin{array}{l}\text { Not taking seriously threats of } \\
\text { emerging infectious disease }\end{array}$ & $\begin{array}{l}\text { Wait-and-see approach in } \\
\text { launching response mechanism }\end{array}$ & $\begin{array}{l}\text { Failure to acknowledge } \\
\text { prior warnings of impacts of } \\
\text { pandemics }\end{array}$ \\
\hline Scientific advice & $\begin{array}{l}\text { Influence of scientific } \\
\text { committees waned over time }\end{array}$ & $\begin{array}{l}\text { Scientific evidence was not } \\
\text { translated into actionable } \\
\text { policies by leadership }\end{array}$ & $\begin{array}{l}\text { Lack of coordination between } \\
\text { scientific committees and } \\
\text { leadership to quickly inform } \\
\text { policy change }\end{array}$ & $\begin{array}{l}\text { Leadership appeared sceptical or } \\
\text { dismissive of emerging scientific } \\
\text { evidence, eroding public trust }\end{array}$ \\
\hline Governance and leadership & $\begin{array}{l}\text { Lack of coordination between } \\
\text { national and subnational } \\
\text { responses }\end{array}$ & $\begin{array}{l}\text { Refusal to take action or } \\
\text { responsibility for the response }\end{array}$ & $\begin{array}{l}\text { Wait-and-see approach to } \\
\text { decisions or changing course } \\
\text { based on evidence }\end{array}$ & Politicising the pandemic \\
\hline Health systems and services & $\begin{array}{l}\text { Historically fragmented and/ } \\
\text { or resource constrained health } \\
\text { systems }\end{array}$ & $\begin{array}{l}\text { Covid-19 testing and care not } \\
\text { universally covered }\end{array}$ & $\begin{array}{l}\text { Reactionary measures to } \\
\text { increase health system capacity. } \\
\text { Fewer mechanisms to link } \\
\text { patients to primary care for } \\
\text { routine care }\end{array}$ & $\begin{array}{l}\text { Hesitancy to seek care, given } \\
\text { overcrowding and high case } \\
\text { numbers/fatalities }\end{array}$ \\
\hline Public health & $\begin{array}{l}\text { Historically underfunded } \\
\text { public health systems and } \\
\text { infrastructure }\end{array}$ & $\begin{array}{l}\text { Prioritising single interventions } \\
\text { over comprehensive measures }\end{array}$ & $\begin{array}{l}\text { Delays in widespread testing } \\
\text { and contact tracing before } \\
\text { community transmission }\end{array}$ & $\begin{array}{l}\text { Lack of consistent public support } \\
\text { for public health measures }\end{array}$ \\
\hline Social and economic supports & $\begin{array}{l}\text { Supports were not enough to } \\
\text { make up for lost wages or other } \\
\text { needs }\end{array}$ & $\begin{array}{l}\text { Supports were not maintained } \\
\text { over time or excluded groups }\end{array}$ & $\begin{array}{l}\text { Lack of mechanisms to ensure } \\
\text { widespread access }\end{array}$ & $\begin{array}{l}\text { Unclear eligibility or } \\
\text { misappropriated supports }\end{array}$ \\
\hline
\end{tabular}


a backdrop of pervasive and unchecked vaccine inequity, for many countries and communities the most devastating surges have happened despite the availability of several safe and effective vaccines. Currently, the different strategies are most visibly playing out, as countries and governments start to recognise the endemic nature of covid-19 and decide how to best move forward. ${ }^{29}$ As many countries have embarked on roadmaps to start re-opening borders and economies, governments that prematurely dismiss the continuing severity of the virus pose risks to their populations and the world, as further mutations of SARS-CoV-2 hold potential to reignite surges in regions that have lower vaccine coverage. Countries in the global north have vaccinated most of their populations and are swiftly resuming daily activities, but it is worth remembering that no one is safe until everyone is safe. Two immediate issues arise. The first is a responsibility to close the vaccine gap between vaccine producing/high income countries and low and middle income countries with low access to vaccines. ${ }^{30}$ Second, nations need to retain flexible public health and social measures based on the changing epidemiology and hospital capacities, and be steadfast in implementing these, even when infections rise following re-opening.

\section{Recommendations: responding, preparedness, and transformation}

Given the characteristics of responses to covid-19 thus far, we propose 15 recommendations for global, regional, national, and subnational leaders to navigate the current pandemic as well as future infectious hazards. The role of decision makers, and the political sphere shaping pandemic responses, cannot be underestimated, as covid-19 has laid bare a long known truth-that politics matter in public health. From the local to the global level, pandemic preparedness and responses can never be apolitical. Thus, recommendations must be actionable, but also reflective of, and adaptable to, country or region specificities. Immediate and medium term actions are required urgently, but we argue that national governments must also address structural challenges in the long term for health systems to become more equitable for all. As such, recommendations must capture the requisite complexity necessary to mitigate the health, social, and economic risks the pandemic poses, to prepare for future pandemics and to grasp the opportunities for building more inclusive and equitable societies.
The image of the iceberg captures the complex interplay of factors, drivers, and contexts that need to be reflected in recommendations (fig 1). ${ }^{3132}$ The visible part of the iceberg represents things that are seen, like the public health interventions countries enacted. Just below the water are those programmatic and systems elements that need to be prepared or maintained to support the response. The bottom of the iceberg contains the structural elements that drive behaviour and the underlying values and beliefs that contribute to such behaviour. Covid-19 has revealed the "underbelly" of the iceberg: the political tensions, systemic weaknesses, and vulnerabilities that public health interventions are built on, and that are built into them. It is by reckoning with what has largely remained hidden from view, and how these all factor into health outcomes, that we can learn how to strengthen pandemic responses going forward. We present the recommendations in three pillars that reflect the iceberg metaphor: responding to emergent pandemic threats, preparing and maintaining resilient health systems for pandemic response, and transforming to build intersectional

approaches centred on community trust and enabled by equitable societies.

\section{Responding to emerging pandemic threats}

Progress can be made if nations are equipped to respond to ongoing and novel threats by making science based decisions to protect lives and livelihoods. Early and decisive implementation of public health measures is dependent on well functioning public health infrastructure. Yet, public health measures alone are insufficient as they may not be accessible (vaccines) or feasible (lockdowns) at scale. These measures must be supported by a social safety net and universal health coverage to ensure programmatic sustainability, while enabling widespread adherence, and protecting livelihoods.

1. Apply public health and social measures systematically, comprehensively, and with community partnership in every country at the scale the epidemiological situation requires. All countries must have an explicit strategy agreed at the highest level of government to curb transmission of covid-19. Targeted and timely public health interventions must be centred

\section{React}

- Immediate, proactive, and precautionary responses

- Public health interventions

- Increase health expenditure for public health infrastructure

\section{Prepare and maintain \\ - Resilient health systems \\ - Socioeconomic support for public health measures \\ - Invest in multidisciplinary, inclusive, and truly independent research \\ - UHC and people centred approach \\ - Monitoring, evaluation, and cross country learning}

\section{Transform}

- Build equitable societies and shift mindsets

- Long term social protection measures and health promotion

- Informed, responsible leaders, and effective co-ordination

-Whole-of-society and whole-of-government approach

Fig 1 | The covid-19 iceberg model for pandemic preparedness and response 
on human rights and supported by economic measures. The capacity of the public health system to perform surveillance, testing, contact tracing, and isolation, while upholding human rights, is critical.

2. Strengthen the engagement of local communities as key actors in pandemic preparedness and response and as active promoters of pandemic literacy, through the ability of people to identify, understand, analyse, interpret, and communicate about pandemics.

3. Build resilient and people centred health systems grounded in high quality primary care and integrate the health and public health system together with the long term care sector. This also fosters accountability, inclusion, and trust through responsiveness.

4. Invest in and coordinate risk communication policies and strategies that ensure timeliness, transparency, and accountability. Work with marginalised communities, including those who are digitally excluded, to build trust and resilience in plans that promote health and wellbeing at all times.

5. Establish mechanisms for monitoring and evaluations at country level. Establish independent and impartial national mechanisms for monitoring the health and social care systems at the country level to prepare for further waves of covid-19 and for future pandemics.

\section{Preparing and maintaining systems for pandemic preparedness and response}

Similarly, future pandemic responses must ensure all activities are planned and implemented with actionable, independent, and transparent monitoring and evaluation mechanisms. The architects of pandemic responses, both decision makers and scientific advisers, must be accountable to the communities affected by the pandemic and measures to mitigate its effects. Similarly, while modern surveillance systems generate vast amounts of data, these outputs can be better translated into policy and practice, and international data sharing obligations and mechanisms need to be considered. This is but one aspect of wider debates on cross-country, regional, and global cooperation to better prepare for and respond to global health challenges through routine data sharing centred in human rights. To achieve this, we must acknowledge that collaboration and any form of surveillance, monitoring, and evaluation are intrinsically political and must be addressed as such. ${ }^{3334}$

6. Increase the threshold of national health and social investments to build resilient health and social protection systems, grounded in high quality primary and community health services, and a strong and well supported health workforce, including community health workers.

7. Ensure a renewed commitment to universal health coverage (UHC) to ensure high quality care for all. Achieving UHC requires appropriate financing, not only to prepare for new pandemics, but to ensure that people have access to the health services they need, when and where they need them, without financial hardship.

8. Conduct multisectoral active simulation exercises on a yearly basis as a means of ensuring continuous risk assessment and follow-up action to mitigate risks, improve cross-country learning and accountability, and foster a culture of alertness to respond when needed and at the right time.

9. Invest in biomedical, public health, and social sciences research, build institutional capacities, and establish mechanisms and platforms that allow for, and encourage, the exchange of knowledge, expertise, and innovation.

10. Ensure that national and subnational public health institutions have multidisciplinary capacities, multisectoral reach, and engagement with the private sector and civil society. Evidence based decision making should draw on inputs from across society, with the inclusion of diverse social and professional groups (ie, age, ethnicity, race, class, gender, disability).

\section{Transforming and building resilient and equitable societies}

Effort is needed to prepare and maintain responses grounded in robust local capacities. Ultimately, the only true preparedness is transformational change that prioritises global solidarity, and protects the health and wellbeing of people, communities, and the planet. The pandemic has brought to the fore a crisis of governance, highlighting gaps in accountability (at all levels), questioning practices of representation, power relations, and hierarchies. Indeed, political leadership and decision making have been at the heart of responses to covid-19, and are among the determinants for successes and failures of a response. Thus, achieving and sustaining high performing responses requires a shift in mindsets beyond political and economic consideration and towards health promotion across sectors and governance, to create healthy societies.

11. Building resilient and equitable societies requires a serious shift in mindsets to engage with and create policies that reflect the broader social, economic, environmental, and political factors in society. Health programmes and responses to covid-19 must no longer remain gender neutral and community blind. A change of paradigms must be accomplished through re-politicisation, foregrounding human rights and equality concerns.

12. Targeted and long term social protection of vulnerable populations should be integral to a whole-of-society approach, and should offer security in terms of food, housing, and income.

13. Implement a collaborative, gender responsive, and equitable whole-ofsociety approach that engages civil society, business, and government at all levels, in acknowledgment of the intersectional nature of health and wellbeing, while also dismantling inherent structural marginalisation and inequalities.

14. Implement a whole-of-government approach that ensures access to health services and protection against discrimination and vulnerabilities.

15. Heads of state and government should appoint national pandemic coordinators accountable to the highest levels of government, with the mandate to drive whole-of-government coordination for both preparedness and response.

\section{Conclusion}

As the covid-19 pandemic evolves, we must consider how to move from response to transformation. The early response laid a foundation that has led us to far reaching health, social, and economic impacts, and amplified existing inequities. To navigate the coming challenges of the pandemic and to prepare for future infectious threats will require deep and transformative action. Countries must learn to partner, coordinate, develop, and strengthen across a range of domains, and we must no longer devalue, deny, delay, and distrust actions that can save lives and livelihoods. To sustain momentum towards such change requires intersectional approaches and a willing ness to learn our lessons and apply them. 
Provenance and peer review: Commissioned; externally peer reviewed.

Contributors and sources: A-SJ, VH, and HL-Q conceived and designed the analysis. A-SJ, VH, RN, SW, MJ, MV, MT, CDF, SMA, PM, AC, and HL-Q collected the data. A-SJ, $V H$, and $H L-Q$ analysed the data and drafted the manuscript with input from all authors. All authors contributed to revising the manuscript. A-SJ studies International Relations and global governance with a specific interest in global health. VH studies health systems and services with a focus on complex programme evaluation and outcomes in resource constrained settings.

This analysis was part of the work commissioned by the Independent Panel for Pandemic Preparedness and Response, which reviewed the national responses of 28 countries. Data used for the analysis was collected through three complementary methods: (1) literature review of peer reviewed papers, policy documents, public reports, and articles that examined national and sub-national policy responses, (2) semi-structured interviews with country experts and national government written submission of selected countries about their own account of the measures implemented to contain covid-19, (3) validation of country specific data by experts through written consultation and round table discussion.

Data for this analysis were collected under the auspices of the Independent Panel for Pandemic Preparedness and Response. The analysis of this paper is separate from the Independent Panel's Fina Report and has been facilitated by the Independent Panel Secretariat. The Secretariat of the Independent Panel for Pandemic Preparedness and Response is independent and impartial. The views expressed in this work are solely those of the authors' and do not represent the views of the Independent Panel for Pandemic Preparedness and Response.

Patient involvement: No patients were involved in this analysis.

\section{Competing interests: We have read and understood} The BM/ policy on declaration of interests and have the following interests to declare: All authors declare no conflict of interest. The Secretariat of the Independent Panel for Pandemic Preparedness and Response is independent.

This collection of articles was proposed by The Independent Panel for Pandemic Preparedness and Response; open access fees were funded by WHO and Singapore's National Medical Research Council (NMRC/CG/C026/2017_NUHS). The BMJ commissioned, peer reviewed, edited, and made the decision to publish these articles. Kamran Abbasi was the lead editor for The BMI.

Victoria Haldane, researcher ${ }^{1}$

Anne-Sophie Jung, research fellow ${ }^{2}$

Rachel Neill, researcher ${ }^{3}$

Sudhvir Singh, adviser, honorary academic ${ }^{4}$

Shishi Wu, research fellow ${ }^{5}$

Margaret Jamieson, researcher ${ }^{2}$

Monica Verma, researcher ${ }^{6}$

Melisa Tan, researcher ${ }^{6}$

Chuan De Foo, research associate ${ }^{6}$

Salma M Abdalla, research fellow, secretariat member ${ }^{4,7}$

Pami Shrestha, researcher ${ }^{6}$

Alvin Qijia Chua, research associate ${ }^{6}$

Anders Nordström, head of the secretariat ${ }^{4}$

Helena Legido-Quigley, associate professor ${ }^{1,4,6}$

${ }^{1}$ Department of Global Health \& Development, London School of Hygiene and Tropical Medicine, UK

${ }^{2}$ Institute of Health Policy, Management and

Evaluation, University of Toronto, Canada
${ }^{3}$ Johns Hopkins Bloomberg School of Public Health, USA

${ }^{4}$ The Independent Panel for Pandemic Preparedness and Response Secretariat

${ }^{5}$ Dalla Lana School of Public Health, University of Toronto, Canada

${ }^{6}$ Saw Swee Hock School of Public Health, National University of Singapore and NUHS, Singapore

${ }^{7}$ School of Public Health, Boston University, USA

Correspondence to: H Legido-Quigley

ephhlq@nus.edu.sg

\section{(c) (1) @ OPEN ACCESS}

This is an Open Access article distributed under the terms of the Creative Commons Attribution IGO License (https://creativecommons.org/licenses/ by-nc/3.0/igo/), which permits use, distribution, and reproduction for non-commercial purposes in any medium, provided the original work is properly cited.

\section{Check for updates}

1 The Independent Panel for Pandemic Preparedness \& Response. COVID-19: make it the last pandemic. 2021.

2 World Health Organization. Strengthening preparedness for health emergencies: implementation of the International Health Regulations (2005). https://apps.who.int/gb/ebwha/ pdf_files/EB148/B148_19-en.pdf

3 Lavine JS, Bjornstad ON, Antia R. Immunological characteristics govern the transition of COVID-19 to endemicity. Science 2021;371:741-5. PubMed doi:10.1126/science.abe6522

4 Douglas M, Katikireddi SV, Taulbut M, McKee M, McCartney G. Mitigating the wider health effects of covid-19 pandemic response. BMJ 2020;369:m1557. PubMed doi:10.1136/bmj.m1557

5 Wouters OJ, Shadlen KC, Salcher-Konrad M, et al. Challenges in ensuring global access to COVID-19 vaccines: production, affordability, allocation, and deployment. Lancet 2021;397:1023-34. PubMed doi:10.1016/S0140-6736(21)00306-8

6 Greer S, King J, da Fonseca E, Peralta-Santos A. Coronavirus Politics: The comparative politics and policy of COVID-19. University of Michigan Press, 2021 doi:10.3998/mpub.11927713.

7 Taylor L. Uruguay is winning against covid-19. This is how. BM/ 2020;370:m3575. PubMed doi:10.1136/ bmj.m3575

8 Uruguay Presdiency. Medidas del Gobierno para atender la emergencia sanitaria por coronavirus (COVID-19). 14 March 2020 2020. https://www. gub.uy/presidencia/politicas-y-gestion/medidasdel-gobierno-para-atender-emergencia-sanitariacoronavirus-covid-19

9 PR anuncia reforço das medidas de prevenção do COVID-19 (press release). Maputo, 20 March 2020 2020

10 Tay J, Ng YF, Cutter JL, James L. Influenza A (H1N1 2009) pandemic in Singapore--public health control measures implemented and lessons learnt. Ann Acad Med Singap 2010;39:313. PubMed

11 Chua AQ, Tan MMJ, Verma M, et al. Health system resilience in managing the COVID-19 pandemic: lessons from Singapore. BMJ Glob Health 2020;5:e003317. PubMed doi:10.1136/ bmjgh-2020-003317

12 Manauis CM, Loh M, Kwan J, et al. Bracing for impact: operational upshots from the National Centre for Infectious Diseases Screening Centre (Singapore) during the COVID-19 outbreak. J Am Coll Emerg Physicians 2020;1:549-56.

13 Park J, Chung E. Learning from past pandemic governance: Early response and Public-Private Partnerships in testing of COVID-19 in South Korea. World Dev 2021;137:105198. PubMed doi:10.1016/j.worlddev.2020.105198
14 Kaweenuttayanon N, Pattanarattanamolee R, Sorncha N, Nakahara S. Community surveillance of COVID-19 by village health volunteers, Thailand Bull World Health Organ 2021;99:393-7. PubMed doi:10.2471/BLT.20.274308

15 Jefferies S, French N, Gilkison C, et al. COVID-19 in New Zealand and the impact of the national response: a descriptive epidemiological study. Lancet Public Health 2020:5:e612-23. PubMed doi:10.1016/S2468-2667(20)30225-5

16 Government NZ. Access to food or essential items 2020

17 New Zealand Ministry of Health. Initial COVID-19 Māori Response Action Plan 2020. https://www. health.govt.nz/publication/initial-covid-19-maoriresponse-action-plan.

18 Chiriboga D, Garay J, Buss P, Madrigal RS, Rispel LC. Health inequity during the COVID-19 pandemic: a cry for ethical global leadership. Lancet 2020;395:1690-1. PubMed doi:10.1016/S01406736(20)31145-4

19 Lopes F;. From denial to hope: Brazil deals with a prolonged COVID-19 epidemic course. Nat Immunol 2021;22:256-7. PubMed doi:10.1038/s41590 021-00875-8

20 Malta M, Vettore MV, da Silva CMFP, Silva AB, Strathdee SA. Political neglect of COVID-19 and the public health consequences in Brazil: The high costs of science denial. EClinicalMedicine 2021;35:100878. PubMed doi:10.1016/j.eclinm.2021.100878

21 McKee M, Stuckler D. Scientific divisions on covid-19: not what they might seem. BMJ 2020;371:m4024. PubMed doi:10.1136/bmj.m4024

22 Maani N, Galea S. COVID-19 and Underinvestment in the Public Health Infrastructure of the United States. Milbank Q 2020;98:250-9. PubMed doi:10.1111/1468-0009.12463

23 Mehra P. A different economic approach. The Hindu. 3 April 2020.

24 Rawal V, Manickem K, Rawal V. Are Distress Deaths Necessary Collateral Damage of Covid-19 Response? 2020 https://www.networkideas.org/ featured-themes/2020/04/are-distress-deathsnecessary-collateral-damage-of-COVID-19-response the-experience-of-first-three-weeks-of-the-lockdownin-india/.

25 Scally G, Jacobson B, Abbasi K. The UK’s public health response to covid-19. BM/ 2020;369:m1932. PubMed doi:10.1136/bmj.m1932

26 Alwan NA, Bhopal R, Burgess RA, et al; 36 signatories. Evidence informing the UK's COVID-19 public health response must be transparent. Lancet 2020;395:1036 7. PubMed doi:10.1016/S0140-6736(20)30667-X

27 Stowe J, Smith H, Thurland K, Ramsay ME, Andrews N, Ladhani SN. Stillbirths During the COVID-19 Pandemic in England, April-June 2020. JAMA 2021;325:86-7. PubMed doi:10.1001/jama.2020.21369

28 Uganda: 'Deteriorating' human rights situation in run-up to elections next week (press release). 8 January 2021.

29 De Foo C, Grépin KA, Cook AR, et al. Navigating from SARS-CoV-2 elimination to endemicity in Australia, Hong Kong, New Zealand, and Singapore. Lancet 2021;398:1547-51. PubMed doi:10.1016/S01406736(21)02186-3

30 Burki T. Global COVID-19 vaccine inequity. Lancet Infect Dis 2021;21:922-3. PubMed doi:10.1016/ S1473-3099(21)00344-3

31 Kim D. Introduction to Systems Thinking. 1999.

32 Maani K, Cavana RY. Systems Thinking, System Dynamics: Managing Change and Complexity. Prentice Hall, 2007

33 Kickbusch I. The political determinants of health--10 years on. BMJ 2015;350:h81. PubMed doi:10.1136/ bmj.h81

34 Ballard M, Bancroft E, Nesbit J, et al. Prioritising the role of community health workers in the COVID-19 response. BMJ Glob Health 2020;5:e002550. PubMed doi:10.1136/bmigh-2020-002550 